\title{
In Favour of Dispositional Explanations. A Christian Philosophy Perspective with Some References to Economics
}

\author{
ŁUKASZ HARDT \\ University of Warsaw \\ lhardt@wne.uw.edu.pl \\ ORCID: 0000-0001-6542-5833
}

\begin{abstract}
From among philosophical concepts of explanation those referring to causes have been the most influential. The aim of this paper it to show that a particular kind of causal explanations, namely dispositional explanations are particularly suited to explain the workings of the world. Apart from purely philosophical arguments, I claim that the view treating dispositions as important elements of the basic ontology of nature is in line with the Christian worldview and the ways God impacts the world. Also, this paper shows that dispositional explanations are not only appropriate in the domains studied by natural sciences but also in the ones being under investigation in social sciences, and thus the case of economics.
\end{abstract}

Keywords: philosophy of causality, dispositional explanations, divine action and natural world, philosophy of economics.

Nature loves to hide.

Heraclitus

\section{Introduction}

Science aims to produce more and more accurate explanations of how the world works. Traditionally, the focus of science on providing knowledge 
and understanding has been its main goal, regardless of its potential applications. However, there is also a widespread agreement that the better explanation a given theory provides, the greater its potential for offering more accurate prediction as well as supplying us with possibilities for its practical use. But still a fundamental question remains: what does it mean to explain a given phenomenon? Classically, in a tradition taking its roots from Aristotle, to explain a phenomenon is to describe its causes. However, in more recent times many other ideas emerged, including the deductive-nomological model of explanation where general laws of nature play a crucial role, the inductive-statistical model of explanation where statistical laws govern the world, model-based explanations where accounting for phenomena often does not require appealing to laws, and many more. Therefore, many philosophers opt for explanatory pluralism (see, e.g., Mantzavinos 2016), however, as this paper shows, there are conceptions of explanation that fit particularly well with the ways the world works, and thus my focus in this paper on one of such ideas, namely dispositional explanations.

The goal of this paper is threefold. First, I show that a fruitful way of viewing causal explanations is to claim that dispositions, powers, and capacities can make things happen. In other words, it is shown that we should allow direct explanatory power of disposition ascriptions (Mumford 2008). Second, I claim that the view treating dispositions as important elements of the basic ontology of nature is in line with the Christian worldview, and in particular with a fundamental belief that the dynamics of the world is ultimately due to God's acting. Third, I offer some illustrations taken from economics and therefore I claim that we should treat many statements of economic theories as statements of dispositions only (cf. Lawson 1997). Therefore, this paper should be treated as a case for scientific realism. Also, it should be read as an invitation for a more intensive collaboration between philosophers of science (and philosophers of economics in particular) and theologians. Last but not least, it shows that references to dispositions, powers, and capacities can be legitimately used not only in its original domain of natural sciences but also in social sciences, and therefore the case of economics (see, e.g., Cartwright 1999). 
This paper is organized as follows. In section 1 the ideas of dispositions, powers, and capacities are introduced together with some definitional clarifications. Also, some metaphysics of dispositions is presented there. Next, in section 2, the emphasis is put on dispositional explanations. In what follows, in section 3 , a Christian philosophy perspective is taken and thus dispositions are seen as an aspect of God's creative power. Section 4 illustrates some ideas of here presented philosophy of dispositional explanations by referring to economics. Conclusions follow.

\section{Dispositions, powers, and capacities}

We all attribute dispositional properties to various objects. When we claim that a particular vase is fragile we attribute a dispositional property, precisely fragility, to the vase. Other examples include solubility of a substance, combustibility of petrol, flammability of hydrogen, elasticity of a rubber band or the ability of aspirin to relieve headache. Additionally, dispositional terms are not reserved to objects and substances. They are used in descriptions of such physical properties as, for instance, mass, charge, or spin of fundamental particles. Moreover, we all use dispositional properties while describing traits of individuals' behaviour, and hence, for instance, references to agility, smartness, versatility, friendliness, and so on. Therefore, as Schultz (2009) observes, “[...] we inevitably encounter things that appear to involve 'a capacity', 'a power', 'inclination', 'habit', 'propensity', 'proclivity', 'tendency', 'capability', 'ability', 'aptitude', or some other such thing" (321-322). For the sake of simplicity let us treat for a while the above terms, dispositions included, as synonymous.

But what does a given disposition, say fragility of the vase, mean? It means that in particular circumstances a given vase can be easily broken. However, a particular vase can be legitimately described as being fragile even without any instances or manifestations of its fragility. Therefore, "To each disposition there corresponds a typical manifestation but a disposition ascription can be true though no manifestations occurs" (Mumford 2008, 5). Also, a given disposition can have multiple manifestations. For instance, the elasticity of a rubber can lead to its contracting, bounc- 
ing, deforming, and the like. The very existence of unmanifested dispositions raises the issue of stimulus conditions as well as possible countervailing factors. For instance, a stimulus condition for a given vase to be broken can be knocking it hardly, however, even after being knocked strongly it can still be unbroken if somebody catches it fast enough. So, in terms of the simple conditional analysis we can write the following:

Definition 1. $x$ (e.g., a particular vase) is disposed to manifest $M$ (e.g., a particular vase being broken into pieces) in response to stimulus $S$ (e.g., somebody hitting this very vase) iff were $x$ to receive stimulus $S$ it would manifest $M^{\top}$.

Now, we can supplement the above definition by adding the possibility of masks, namely countervailing factors:

Definition 2. $x$ is disposed to manifest $M$ in response to stimulus $S$ without a particular mask $N$ (e.g., somebody catching this very vase) iff were $x$ to receive stimulus $S$ it would manifest $M^{2}$.

Another interesting issue with dispositions is that a given object can lose its particular disposition. For instance, our vase can be heated up and thus it becomes soft and non-fragile ${ }^{3}$. I am to elaborate more on the above introduced analysis on the role of dispositions in producing particular phenomena (dispositions' manifestations) later in the section on dispositional explanations, but now let us put emphasis on the very meaning of disposition. Here I claim that the conditional analysis, or - in other words, the Humean account of dispositions, does not properly account for what dispositions are, since it reduces dispositions to mere things' behaviours (e.g., claims about sugar solubility arise from previous experience of sugar dissolving and not from refereeing to sugar's inner characteristics) (see, similar arguments in Mumford 2008). So, some metaphysics of dispositions is necessary.

This definition is due to Bird $(2013,38)$.

In this very definition my task is to only show how references to masks (or antidotes) can be put into the framework of the previously introduced (Definition 1) simple conditional analysis, and thus I do not claim anything about the extent to which conditional analysis can support masks/antidotes. I would like to thank one of the referees for raising this problem.

3 Philosophers describe such situations as cases of finks (Choi 2011). 
Let me start by elaborating on differences between dispositions, powers, and capacities. Now, as far as dispositions are concerned, they are usually defined not only as intrinsic characteristics of a given object but they are primarily understood with a kind of relation to an event they can produce. Therefore, for instance, we find the following characterization of dispositions: " $F$ is a disposition iff there are an associated stimulus condition and manifestation such that, necessarily, $x$ has $F$ only if $x$ would produce the manifestation if it were in the stimulus condition" (Choi 2021).

So, as the above definition shows, dispositions are properties of objects that tell us how they can behave in various circumstances. Such a view is sometimes criticized since there are philosophers who claim that, for instance, ascribing a disposition is not ascribing a property but merely saying how something is to behave in a given situation ${ }^{4}$. For them, dispositions are just fictions and what really matters are regularities. Consequently, they deny the scientific status of dispositions. However, a dominant position in contemporary philosophy is that "[disposition] deserves its place in the vocabulary of scientific theory as a name of a particular state or mechanism" (Quine 1978, 157). Moreover, as dispositional realism asserts, dispositions are genuine occurrent properties that can produce (but not necessarily need to) appropriate manifestations (Chakravartty 2007, 126).

Now, what is then the difference between dispositions and powers? As Harré (1970) explains, the above method of conditional analysis used to define dispositions cannot be employed in case of powers:

Things and materials have powers even when they are not exercising them, and that is a current fact about them, a way in which they are currently differentiated from other things and materials which lack and now lack these powers. Indeed, the reason why we believe that a certain disposition can be asserted truly a thing or material is that we think or indeed know that it currently has such and such powers [...]. The difference between something which has the power to behave in a certain way and something which does not have that power is

4 Such a view takes its roots from the Ryle-Wittgenstein tradition. 
not a difference between what they will do [as it is in the case of dispositions], since it is contingently the case that their powers are, in fact, ever elicited, but it is a difference in what they themselves now are. It is a difference in intrinsic nature (84-85; italics in original).

Therefore, powers are more fundamental than dispositions and they are "properties with a certain kind of essence - an essence that can be characterized in dispositional terms" (Bird 2013, 27). Consequently, the very essence of a given power can be equalized with its nature, and thus "what a power does when exercised is in the nature of that power" (Cartwright and Pemberton 2013, 93). Traditionally, therefore, powers are treated as metaphysically basic and not dependent on any other kind of entity 5 . Also, powers should be possessed permanently by things since they are things' ways of being. Now, one can describe the interplay between dispositions, powers, and natures in the following way: by its very nature a given power can give rise to a certain disposition which can be manifested in right conditions. In other words, and consequently, any entity $x$ having a power $P$, and in virtue of $P$ 's nature, is characterized be a disposition $D$ which makes $x$ disposed to $M$ when $S$.

What is now left for me to deal with in this section is an analysis on how to relate capacities to powers, natures, and dispositions. Let me start with N. Cartwright's take on capacities since she devoted two entire books $(1989 ; 1999)$ in defence of the claim that capacities are prior to laws. Cartwright is thus well known for her denial of the Humean view on laws and causation (Psillos 2008). She writes: “The generic causal claims of science are not reports of regularities but rather ascriptions of capacities, capacities to make things happen [...]" (1989, 2-3).

Firstly, capacities are of properties and not of things having these properties: "[...] the property of being an aspirin carries with it the capacity to cure headaches" (141). Secondly, since capacities are carried by the property of being $x$, and since capacities are prior to laws and regularities, then they should be conceptually close to nature of things. And Cart-

5 Nevertheless, there is an interesting debate on whether powers need grounds, but presenting this very debate here is definitely beyond the scope of this paper. 
wright (1999, e.g., 84-85;) shows it. Thus, and thirdly, in Cartwright's philosophy capacities are somehow in-between powers and dispositions. So, they are close to dispositions since they are defined in terms not only of intrinsic characteristics of properties but also in terms of manifestations they can produce. But they are also close to powers since they have their own nature ${ }^{6}$. Nevertheless, a given thing can lose one of its capacities but it cannot lose its entire nature (e.g., as in the case of the above cited example of the heated up vase).

Now, there is one remaining issue worth analysing, namely of whether all properties are dispositional properties (dispositional monism or, synonymously, dispositionalism). In other words, are categorical properties only a subclass of dispositional properties? ${ }^{7}$ I am sympathetic to this view and I refer in this respect to Cartwright's idea of nomological machine, namely that in ideal conditions a given disposition is categorical in a sense that it always leads to its proper manifestation ${ }^{8}$. However, and consequently, my dispositionalism is not about all properties but mainly the ones that make things happen, or, in Lewis' (1986) sense, about properties that have a dispositional essence. For instance, yellowness is hardly such a property, but solubility is. Also, such dispositionalism holds, following Cartwright, that laws of nature are just descriptions of broadly defined dispositions (Hardt 2017).

We began this section by focusing on dispositions and by showing that they cannot be properly defined without mentioning manifestations they can produce. Obviously, however, in-depth understanding of dispositions requires us to refer to powers, capacities, and natures, and this

6 See, for instance, Psillos (2008) for more insights regarding the interplay between capacities and natures.

7 Although defining categorical properties is at least as difficult as in the case of dispositional ones, there is however a broad consensus that ascriptions to dispositional properties entail counterfactual conditionals whilst categorical ones do not. Also, as Mumford (2008, 37; italics in original) puts it: "Dispositions ascriptions are categorical in the sense that to say that something has a dispositional property is to say that something has a property actually".

8 Cartwright (1999) defines nomological machines in the following way: "It is a fixed (enough) arrangement of components, or factors, with stable (enough) capacities that in the right sort of stable (enough) environment will, with repeated operation, give rise to the kind of regular behaviour that we represent in our scientific laws" (50). 
is what we did in this section. Nevertheless, in the next section which focuses on dispositional explanations we are mainly putting emphasis on the role of depositions in producing various phenomena without any further study into ontology of dispositions. We come back to these issues later in section 3 when we try to look at dispositions from the theological perspective.

\section{Dispositional explanations}

Interestingly, when searching for the origin of philosophical reflection on explaining looking at Greek words used by ancient thinkers helps a lot. Here the Greek noun 'aitia' is particularly important, together with its cognate adjective 'aitios', and 'aition'. Traditionally, 'aitia' is translated as a cause, however, many prefer to interpret this very word as an explanation of something (Broadie 2012). As Aristotle writes: "[...] we do not think to know a thing till we have grasped the 'why' of it (which is to grasp its primary cause)" (Physics, 2.3, 194b16).

If we agree that causes are explanatory, then the following question emerges: are dispositions causes of things? I subscribe here to those philosophers answering this question positively by treating dispositions as causally efficacious and at the same time by viewing dispositions as properties of things ${ }^{9}$. Mumford (2008) offers convincing arguments for such a view, and he gives the following illustration:

If type-identical stimuli are applied to two objects and one reacts differently from the other, then the difference in reaction must be accounted for in terms of some difference between the objects and this is a difference that has a causal effect on the reaction [...]. For instance [...], the ascription of solubility would have to be taken as an ascription of something that is causally efficacious of such behaviour in such conditions, namely, a property of the object (14-15; italics in original).

9 Some arguments for treating dispositions as things' properties were given in Section 1. 
So, dispositional statements are statements about dispositions that are real and not about some law-like regularities (Cartwright 1999). Therefore, on such a view denying the existence of covering laws of nature, one cannot reinterpret Definition 1 from the previous section along the lines of the nomological-deductive model of explanation ${ }^{10}$. In other words, dispositions are causes par excellence ${ }^{11}$. Thus the general structure of dispositional explanations can be approximated in the following way where $C$ stands for conditions and $E$ for explanation (let me denote the below as Definition 3):

$C_{1}: \quad y$ was in a situation of the kind $Z$,

$C_{2}: \quad y$ has the property $N$ that disposes behaviour $R$ in a situation of kind $Z$,

E: $\quad y$ behaved in manner $R$.

So, dispositions do what laws do in other theories of explanation. However, dispositional explanations allow for exceptions, for instance, claiming that water is disposed to boil at $100^{\circ} \mathrm{C}$ does not exclude a possibility that for some reasons a given amount of water is not to boil at $100^{\circ} \mathrm{C}$. On the other hand, a law statement that all water boils at $100^{\circ} \mathrm{C}$ does not allow for exceptions. But what about statistical laws, e.g., heating water up to $100^{\circ} \mathrm{C}$ raises the probability that it is to boil? Or, in other words, is it legitimate to interpret dispositional explanations in statistical terms? Here the literature focusing on normic laws and non-monotonic logic suggests that we should distinguish between prototypical and statistical normality. For instance, the sentence 'birds normally fly' (or, in our terms, 'birds are disposed to fly') refers to prototypical normality, i.e., the capability to fly is a prototypical characteristic of birds. Such a sentence is to be true even in the case of ecological catastrophe when birds lose their

10 Covering laws of nature are understood here in the sense of Hempel and Oppenheim (1948).

11 An interesting issue arises here, namely to what extent one can argue for dispositional explanations and at the same time denying that they are causal explanations. I am generally quite sceptical regarding non-causal dispositional explanations (see, also, e.g., Mumford 2008). I would like to thank one of the referees for rising this issue. 
ability to fly (e.g., due to oil sticking their wings together). On the other hand, claiming that 'being a bird raises the probability of being able to fly' denotes statistical normality. Without any instances of a flying bird such a sentence has hardly any sense. These ideas of normality are closely related but prototypical normality (or, in our terms, dispositional normality) does not reduce itself to statistical normality. Or, in other words, sticking to our birds example, once they all lose their ability to fly due to ecological catastrophe then they will become extinct after a short period of evolution. So, as Schurz $(2004,196)$ claims, "prototypical and statistical normality are connected by the law of evolutionary selection". Such a statement, however, has many weaknesses (e.g., not all prototypical features of individuals have, or had, a selective advantage in evolution) and thus should be seen only as a very simplified unifying framework linking prototypical and statistical normality. Nevertheless, dispositional properties of things are explanatory and can give us knowledge on how the world works.

Now, let me come back to dispositions treated as properties making things happen in right circumstances. For instance, we may have a billiard ball (say ball no 12) moving fast on a typical billiard table which is thus disposed to move other balls once they collide. Imagine that this very ball hits a ball no 5 , so one may say that it caused a ball no 5 to move. However, it happens only in right circumstances, and thus in our example also the force of gravity plays an important role, not to cite the absence of somebody taking balls off the table. Therefore, the gravitation operates here as an "insufficient but non-redundant part of an unnecessary but sufficient" condition for the ball no 5 to be hit by the ball no 12 (the so-called INUS condition) ${ }^{12}$. So, in more general terms, a situation of the kind $Z$ in Definition 3 should be only treated as an INUS condition for $y$ behaving in manner $R$ due to factors cited in $C_{2}$. But please notice here that I do not treat INUS conditions as a way to enable exceptions in the regularity based view on causation but only to show how complex the workings of causal fields are (cf. Hausman 1998).

12 See, Mackie (1974) for an original debate regarding INUS conditions. 
The here presented view focusing on causal powers and dispositions is an attempt to disclose what causality really is, and it is not just an account of phenomena that accompany causality like in, for instance, the Humean approach to causality. Therefore, a need for the ontology of explanation and we have already offered such an analysis in Section 1. Now, I would like to make a step further and to show in the next section that causally explaining phenomena by referring to dispositions is compatible with the way God governs the world. As Artigas puts it, "[...] divine action conceived as the activity proper to a First Causes is absolutely compatible with the agency of natural causes" $(2001,20)$. Or, in straightforward words of Koperski, “dispositionalism allows for divine action” (2020, 94). Later, in Section 4, I show that the here presented perspective on dispositional explanations can be applied not only to natural realm but also to social one, and thus the case of economics.

\section{Dispositional explanations and divine action}

Volumes were written about the ways God impacts natural world. For instance, one can subscribe to the Thomistic view that divine action is based on primary and secondary causation. The former is reserved for God who as a necessary being is the sole uncaused cause, and everything else is secondary. Since natural sciences study only secondary causes, then it is often claimed that God does not intervene at this very level. However, as Dodds rightly claims, "When a primary and secondary cause act together, however, the effect belongs entirely to both. The influence of the primary cause does not diminish the action of the secondary cause, but enables it" (2016, 192). In a similar vein, Artigas (2001, 145) observes the following: "[...] divine and natural causality must have something in common, insofar as in both cases we are dealing with causes that produce effects". It should not surprise us having in mind the following Aquinas' words: "God is the cause or the action of all things inasmuch as he gives them power to act and preserves them and applies them to action and inasmuch as by his power every other power acts" (De Potentia, q.3 q.7). So, it is natural for 
those believing in dispositions, natures, and powers to favour this aspect of Thomism.

Now, since dispositionalism allows (or even requires) indeterminism and since it rejects the notion of natural laws understood as omnitemporally and omnispatially true universal regularities, then it comes close to the doctrine of nonviolationism regarding the nature of divine action. Here nonviolationism is defined as a position claiming that God actively governs the world but at the same time that he does not break the laws of nature $^{13}$. And again, what matters here is how to understand laws of nature. If they are Humean regularities, then nonviolationism is untenable. But if they are statements about dispositions, as it is here claimed, then, for instance, God can be claimed to act either by changing a particular disposition or by influencing the conditions in which such a disposition operates. The former position is taken by Göcke (2015, 223) who claims the following: "[The] only thing God has to do in order to bring about a particular effect is to change temporarily the dispositions of the natural kind(s) that will constitute the state of affairs that God's special act of intervention intends to bring about”.

However, the problem I have with such a view is that it possibly allows for too much of God's activity in the world. Now, what about the second possibility, namely that God acts not by changing dispositions but by changing circumstances? The same problem arrives but maybe to a lesser extent. How such a problem can be overcome? Well, we have at least two possible solutions. First, when there is no determinism in the world then a given disposition acting in given circumstances should not necessarily lead to a predetermined effect. Second, it should be checked whether creating ideal conditions, namely the ones that always give rise to a regular and predetermined behaviour, is possible in the world we live in. Or, in other words, whether Cartwright's nomological machines can occur naturally in nature.

Let me start with determinism, but what does this term mean? Well, for many scholars and also in common sense thinking determinism is linked with predictability of events. Think, for instance, about a "Lapla-

13 This definition is taken from Koperski (2020). 
cian demon", and if it exists, then definitely there is no place for divine action: "If Laplace were right, for example, and a strict determinism would allow us to predict all future states and retrodict all past ones, then there would truly be no place for divine action" (Clayton 1997, 206). However, as contemporary physics proves it, such a determinism is generally untenable. And thus, as Koperski $(2020,120)$ claims, “[...] if determinism is what modern physics takes it to be [...] it will not be a bar to divine action. If some aspect of physics prevents divine action, determinism will not be it". Also, as Davies (1992) stresses, “[...] even accepting a strictly deterministic account of nature, the future states of the Universe are in some sense 'open”" (221).

And, finally, as Artigas observes, "[...] thanks to new theories of deterministic chaos, we are now beginning to see how an adequate dose of chance combined with another dose of determinism can provide the basis for an enormous repertoire of possibilities in the natural world" (2001, 105).

Decades ago the very term 'deterministic chaos' would have been treated as an oxymoron, and now it can be treated as a kind of a middle ground between chaotic and indeterministic world and the world where any kind of novelty is simply impossible. So, such a dappled and open world where "Laplacian demon" does not exist enables divine action that impacts dispositions without eliminating creativity of nature and human freedom.

Now, let me investigate the second solution to my problem, namely the one that refers to the impossibility of creating such ideal conditions for a given disposition that always give rise to a predetermined set of regularities. Here Cartwright's reflection on nomological machines helps, since she claims that "more often [the nomological machines] are engineered by us, as in laboratory experiments" $(1999,49)$. So, and most probably, there are no such circumstances in nature that can guarantee a given disposition to always produce an a priori predictable manifestation. This is due to the fact that these circumstances are only INUS conditions for a given disposition to produce a particular manifestation (see, section 2). But also because manifestations are polygenetic, namely they 
are produced by many dispositions that interact 'chemically' rather than purely 'mechanically' (Molnar 2003). So, and again, nature is not deterministic, at least both in sense of Spinoza and Leibniz, and thus its creativity and openness.

So, having said the above, it seems that it is possible to claim that God impacting dispositions does not endanger the view of the world offered by modern science ${ }^{14}$. This is mainly due to the fact that our knowledge about the world is about dispositions, powers, and capacities (Cartwright $1989 ; 1999)$. And the world of powers does not imply any form of predictabilism. What is therefore interesting is how philosophers proclaiming the return to Aristotelian-like dispositions understand the role of divine action in the world. Let me focus on N. Cartwright who is definitely one of the best known philosophers working in this tradition. In her reply to P. Allport she claims the following: "I think that in the concept of law there is a little too much of God. We try to finesse the issue with possible worlds, fictive regularities, and ceteris paribus clauses. But in the end the concept of a law does not make sense without the supposition of a lawgiver" (1993, 299).

Next, in an essay No God, No Laws (2004) she offers such a conclusion: "None of the four contemporary accounts of laws [empiricism, Platonism, instrumentalism, and Aristotelianism] that I have reported on can make sense of laws of nature without God. The last, Aristotelianism, can offer a stand-in for laws - natural powers - that satisfies the major requirements on laws without the need to call on God" (24).

Interestingly, however, in a small footnote to the above passage she adds: "This does not of course have consequences one way or another for the prior question, 'Is God necessary to create the material world with its powers?'” (ibid.)

Therefore, she is not denying the very existence of God, however, she builds her philosophy as if God does not exist. One reason for such an attitude is her general denial of fundamentalism, precisely - in her un-

14 It is definitely a very complex issue, however, elaborating more on it is definitely beyond the scope of my paper. Interested readers can consult, for instance, Freddoso (1991) and his discussion on occasionalism, mere conservationism, and concurrentism. 
derstanding, the doctrine that the world is governed by laws of nature. Or, in other words, she is against the doctrine of nomological realism which claims that laws are fundamental and cannot be reduced to lawlike-statements and also that laws do not supervene on powers. So, since she links laws of nature with God, then rejecting laws of nature leads her to a general scepticism regarding law-giver, namely God. Although, and a bit paradoxically (at least from her own standpoint), she does not refer directly to God, her philosophy - being metaphysically rich - is definitely closer to the view accepting the role of God in the workings of the world than to traditions like positivism or Humean empiricism where there is not only no place for God but where there is no place at all for any kind of metaphysics. Last but not least, her denial of occasionalism can be interpreted as a sign of openness to more sophisticated philosophies allowing for acting God in the world of powers.

Now, dealing with causal theories of explanation, and in particular focusing on dispositional explanations, raises another important question: is a downward causation possible, and precisely can manifestations impact their causes (here dispositions resulting from powers)? Also, if we allow for such a causation, then is it to be in agreement with the ways God impacts the world? Interestingly, Cartwright's philosophy is again a useful point to start with. She is antireductionist, and thus manifestations do not reduce to their effects, hence emergence. So, she writes: "[...] you can hive the force off from the situation, and conceive it to exist altogether apart from the situation" $(1999,45)$.

The above proves that she accepts, at least to some extent, the possibility of the so-called ontological emergence, namely a view that macrolevel properties are irreducible and real (O’Connor 2020). Such a position can hold only with respect to systems that are open at micro-level, and the ones being governed by dispositions are such systems. Also, there are many examples of downward causation, e.g., the one of human consciousness. So, we can have a kind of ontological novelty present on higher-levels of reality. Therefore, if we allow God to impact higher levels of nature, then it does not endanger our view of the world as the world of dispositions. Peacocke $(1993,159)$ explains it as follows: "If God inter- 
acts with the 'world' at this supervenient level of totality, then he could be causatively effective in a 'top-down' manner without abrogating the laws and regularities [...] that operate at the myriad sub-levels of existence that constitute that 'world'". And I would add that also without abrogating dispositions, powers, and natures. Such a universe in which there is room for both emergence and acting powers (dispositions) is, by definition, an open world, and only such a world can be the one compatible with the ways God impacts this very world (cf. Artigas 2001).

After all that have been already said above, it is time to offer an illustration of the here presented meta-theoretical framework, and so I take it from a particular science using explanations that can be qualified as dispositional ones. I chose economics which is now widely studied by philosophers as a science which nicely fits with the ideas of dispositions, powers, and capacities (see, e.g., Cartwright (2007), Lawson (1997), Crespo (2013), and Hardt (2017)).

\section{Dispositional explanations in economics}

It is easily noticed that in everyday language we ascribe dispositions to people. For instance, one may say that John's friendliness makes him predisposed to have many friends. But can we rigorously and scientifically explain human behaviour in dispositional terms? I answer this very question positively, however, some differences between human dispositions and the ones of the objects of the material world should be noticed. Let me nevertheless start by referring to some fundamental words by Hempel regarding this issue:

"One kind of explanation that has been held to defy covering-Iaw analysis invokes in a characteristic manner certain dispositional properties of the objects or agents whose 'behavior' is to be accounted for; I will refer to this procedure as dispositional explanation. The familiar method of explaining human decisions and actions [...] is to assign to him certain more or less complex dispositional characteristics" $(1978,137)$ 
Therefore, at least in the above Hempel's opinion, not only elements of empirical world are characterised by dispositions they possess but also human action can be explained in dispositional terms, and since economics is a science focusing on explaining human choices then we may expect dispositional explanations to be present in this particular science ${ }^{15}$. Therefore, for instance, the following statement taken from a given economic theory: 'lowering cost of money raises firms' investment', should be best interpreted in dispositional terms, namely that lowering cost of money makes investments disposed to rise. Therefore, statements of economic theories are at best tendency statements. Such is also an old view on economic laws proposed by J.S. Mill: "All laws of causation, in consequence of their liability to be counteracted, require to be stated in words affirmative of tendencies only, and not of actual results" (1843, 523). But still, are such laws dispositional explanations? Definitely so, and here I fully agree with Cartwright saying that "Substituting the word 'capacity' for Mill's word 'tendency', his claim is exactly what I aim to establish" (1989, 170), and also for the sake of simplicity let us treat dispositions as synonymous to capacities. Therefore, for instance, our above statement on money and investment can be rewritten in the following way: lowering cost of money creates a tendency of firms' investments to rise. But still, are dispositions of cheap money ontologically similar to the ones of, for instance, an excited atom? In Cartwright's opinion: “[...] our typical methodologies and our typical applications, both in the natural and in the social sciences, belong to a world governed by capacities” (1989, 1-2).

So, the social realm is the realm of potentialities and definitely not of actualities only. In Lawson's words: “[...] these or related notions [lawlike statements in economics] must be conceived in terms of potentials; as potentials that may or may not be expressed, and if expressed that may or may not be actualized because of countervailing tendencies [...]" (1997, 106). Interestingly, however, dispositions in the social realm are more complex than the ones in the world studied by natural sciences:

15 Here I refer to a classical definition of economics due to Robbins (1932), precisely "the science which studies human behaviour as a relationship between ends and scarce means which have alternative uses [...]. There are no limitations on the subject-matter of economic science save this". 
"The natural thought about the difference between the most fundamental capacities studied in physics and the capacities studied in economics is that the economic capacities are derived whereas those of fundamental physics are basic" (Cartwright 2007, 54).

However, contrary to Cartwright, although I agree that the majority of capacities described by economics are derived, there are the ones that are fundamental and basic since they are constitutive to human nature. It was after all Aristotle claiming in Politics (I, 2, 1253a; 1984, 29-30) that "[...] there is in everyone by nature an impulse towards this sort of partnership [i.e., being with others, including trading with them]". In contemporary philosophical terms, such a position can be named a transcendental realism, namely a position in philosophy of science claiming that the role of science is to explain surface phenomena (here, for instance, economic exchange) by referring to some deeper causal structure (here, human nature $)^{16}$. So, without understanding human nature one cannot fully understand a person, including the place of a human being in the world of market exchange.

Now, why dispositional interpretation of statements of economic theories is so appropriate and in accordance with the ways social realm, including the economic one, works? First, such an interpretation allows for taking into account the possibilities of exceptions, e.g., on dispositional reading saying that diminishing the cost of money leads to higher investments would be still valid even in cases when loose monetary policy does not impact firms' investments. Second, such a reading of statements of economic theories allows us to take into account disturbing factors as well as factors necessary for a given disposition to produce its manifestation. For instance, in case of monetary policy strong price elasticity of firms' demand for investment goods is usually treated as a precondition of a smooth transmission of monetary policy. Such a requirement is an

16 In his take on how to understand the very act of explaining economic phenomena, Lawson $(1997,24)$ writes the following: "It is a movement, paradigmatically, from a 'surface phenomenon' to some 'deeper' causal thing”. 
INUS condition for a loose monetary policy to influence investments ${ }^{17}$. Third, there are definitely places where statements of economic theories always hold, namely they are always right in economic models, e.g., in a Keynesian theoretical model of monetary transmission a decrease in the cost of money always produces a corresponding shift in investments. So, in our terms, such models are blueprints of nomological machines. Therefore, economic models tell us under which conditions given laws arise, but still such laws are statements about dispositions and definitely not about Humean regularities.

The above proposed view of economics and earlier remarks on dispositional explanations fit well with the idea of humble science, here economics. Such a view on science is definitely the one in accordance with a Christian perspective on how we should explain the world we live in. As Saint John Paull II puts it in Fides et Ratio: "Human wisdom refuses to see in its own weakness the possibility of its strength; yet Saint Paul is quick to affirm: 'When I am weak, then I am strong' (2 Cor 12:10)” (no 23). So, I cannot know something for sure, but still I can come closer and closer to truth about a particular problem I am focusing on. In other words, our conception of science should allow imperfect regularities, doubts, errors, approximations, context dependent explanations, emergent properties, and so on; but on the other hand it should offer an account of explanations that are better than others in offering us insights on how the world works. So, a humble science, namely the one based on the right and very Christian understanding of humility which is wisely described by T. Merton: "Humility is a virtue, not a neurosis. A humility that freezes our being and frustrates all healthy activity is not humility at all, but a disguised form of pride" $(1956,55)$. So, dispositional explanations are the ones offering us knowledge about the world but definitely such knowledge is, in a sense, more humble than, for instance, the one described by purely probabilistic views on causation or various branches of nomological realism. Therefore, the very fact that dispositional explanations, including the ones in economics, are in accordance with the idea of humble

17 See, section 2 for a discussion on the meaning of INUS conditions in the context of dispositional explanations. 
science offers us another strong argument for the validity of the here presented perspective on scientific explanations (Hardt 2021).

\section{Concluding remarks}

I hope that after all that have been stated above it is clear that my perspective subscribes to philosophical realism with its claim that "[scientific] method must fit with the nature of its object" (Lawson 2015, 13). So, if the world is the world of powers and dispositions, then explaining it should be done in dispositional terms. Throughout this paper I offered a lot of arguments for the validity of such a worldview, and consequently an in-depth study on dispositional explanations here offered. These issues are raised in the contemporary philosophical literature, for instance, and most notably, by N. Cartwright whose ideas played a special role in my take on dispositional explanations. However, another issue studied here, namely the one on whether viewing scientific explanations in a dispositional manner is in accordance with the ways God impacts the world, is relatively rarely analysed nowadays both by philosophers and theologians ${ }^{18}$. Thus, what I tried to do was to show that dispositions allow for divine action, and that the Christian way of seeing the world as the world of causes can be nicely expanded by taking a dispositional view of causal explanations. However, I am aware that I have only barely touched upon many issues and more research is needed. Lastly, I offered arguments for using the here presented perspective on explanation not only in its original domain of natural sciences but also in social sciences, and thus the case of economics.

\section{References}

Aristotle. 1984. Politics. Chicago: University of Chicago Press.

Artigas Mariano. 2001. The Mind of the Universe. Understanding Science and Religion. London: Templeton Foundation Press.

18 Valuable exceptions include, for instance, Artigas (2001), Schultz (2009), and Koperski (2020). 
Bird, A. 2013. “Limitations of Powers.” In Powers and Capacities in Philosophy. The New Aristotelianism, edited by R. Groff, J. Greco, 25-47. London: Routledge. Broadie, Sarah. 2012. “The Ancient Greeks.” In The Oxford Handbook of Causation, edited by H. Beebee, C. Hitchcock, \& P. Menzies, 73-91. Oxford: Oxford University Press.

Cartwright, Nancy. 1983. How the Laws of Physics Lie. Oxford: Oxford University Press.

Cartwright, Nancy. 1993. “Is Natural Science 'Natural' Enough?: A Reply to Philip Allport.” Synthese 94 (2): 291-301.

Cartwright, Nancy. 1999. The Dappled World: A Study of the Boundaries of Science. Cambridge: Cambridge University Press.

Cartwright, Nancy. 2004. "No God, No laws.” manuscript presented at the conference "God and the laws of nature", organised by the John Templeton Foundation, 11-13 October 2004, http://personal.lse.ac.uk/cartwrig/Papers/NoGodNoLaws.pdf

Cartwright, Nancy. 2007. Hunting Causes and Using them Approaches in Philosophy and Economics. Cambridge: Cambridge University Press.

Cartwright, Nancy, Pemberton, John. 2013. “Aristotelian Powers: Without Them, What Would Modern Science Do?” In Powers and Capacities in Philosophy. The New Aristotelianism, edited by R. Groff, J. Greco, 93-112. London: Routledge.

Chakravartty, Anjan. 2007. A Metaphysics for Scientific Realism: Knowing the Unobservable. Cambridge: Cambridge University Press.

Choi, Sungho. 2011. "Finkish Dispositions and Contextualism.” The Monist 94: 103-120.

Choi, Sungho. 2021. “Dispositions.” In The Stanford Encyclopedia of Philosophy, edited by E.N. Zalta (Spring 2021 Edition). https://plato.stanford.edu/entries/ dispositions/

Clayton, Philip. 1997. God and Contemporary Science. Edinburgh: Edinburgh University Press.

Crespo, Ricardo F. 2013. A Re-Assessment of Aristotle's Economic Thought. London: Routledge.

Davies, Paul C.W. 1992. “Is the Universe a Machine.” In The New Scientist Guide to Chaos, edited by N. Hall. London: Penguin.

Dodds, Michael J. 2016. Unlocking Divine Action: Contemporary Science and Thomas Aquinas. Washington DC: Catholic University of America Press.

Freddoso, Alfredo J. 1991. "God's General Concurrence with Secondary Causes: Why Conservation Is Not Enough.” Philosophical Perspectives 5: 553-585. 
Göcke, Benedikt Paul. 2015. "Did God Do It? Metaphysical Models and Theological Hermeneutics.” International Journal for Philosophy of Religion 78 (2): 215-231. Hardt, Łukasz. 2017. Economics without Laws. Towards a New Philosophy of Economics. Cham: Palgrave.

Hardt, Łukasz. 2021. “An Essay on Humble Economics.” In Words, Objects and Events in Economics, edited by P. Róna, L. Zsolnai, A. Wincewicz-Price, 13-32. Cham: Springer.

Harré, Rom. 1970. “Powers.” British Journal for the Philosophy of Science 21: 81-101. Hausman, Daniel M. 1998. Causal Asymmetries. Cambridge: Cambridge University Press.

Hempel, Carl G. 1978. “Dispositional Explanations.” In Dispositions, edited by R. Tuomela, 137-146. Dordrecht: Springer.

Hempel, Carl G., Oppenheim, Paul. 1948. "Studies in the Logic of Explanation.” Philosophy of Science 15 (2): 135-175.

Koperski, Jeffrey. 2020. Divine Action, Determinism, and the Laws of Nature. London: Routledge.

Lawson, Tony. 1997. Economics and Reality. London: Routledge.

Lawson, Tony. 2015. Essays on the Nature and State of Modern Economics. Abingdon: Routledge.

Lewis, David. 1986. On the Plurality of Worlds. Oxford: Basil Blackwell.

Mackie, John L. 1974. The Cement of the Universe: A Study of Causation. Oxford: Oxford University Press.

Mantzavinos, Chrysostomos. 2016. Explanatory Pluralism. Cambridge: Cambridge University Press.

Merton T. 1956. Thoughts in Solitude. New York: Farrar, Straus and Cudahy.

Mill, John Stuart. 1843. A System of Logic. Ratiocinative and Inductive. London: John W. Parker.

Molnar, George. 2003. Powers: A Study in Metaphysics. Oxford: Oxford University Press.

Mumford, Stephen. 2008. Dispositions. Oxford: Oxford University Press.

O’Connor, Timothy. 2020. “Emergent Properties.” In The Stanford Encyclopedia of Philosophy, edited by E.N. Zalta (Fall 2020 Edition), https://plato.stanford. edu/archives/fall2020/entries/properties-emergent/

Peacocke, Arthur. 1993. Theology for a Scientific Age: Being and Becoming - Natural, Divine and Human. Minneapolis: SCM Press.

Psillos, Stathis. 2008. "Cartwright's Realist Toil: From Entities to Capacities.” In Nancy Cartwright's Philosophy of Science, edited by L. Bovens, C. Hoefer, and S. Hartmann, 167-195. New York: Routledge. 
Quine, Willard V.O. 1978. “Disposition.” In Dispositions, edited by R. Tuomela, 155-161. Dordrecht: Springer.

Robbins, Lionel. 1932. An Essay on the Nature and Significance of Economic Science. London: Macmillan.

Schultz, Walter John. 2009. “Dispositions, Capacities, and Powers. A Christian Analysis.” Philosophia Christi 11 (2): 221-238.

Schurz, Gerhard. 2004. "Normic Laws, Nonmonotonic Reasoning, and the Unity of Science." In Logic, Epistemology, and the Unity of Science, edited by S. Rahman, 181-211. Dordrecht: Kluwer. 
